\title{
Fındık altında yetişen yaygın fiğ+tahıl karışımlarının ot veriminin belirlenmesi*
}

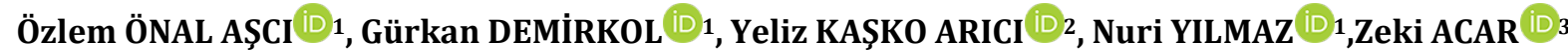 \\ ${ }^{1}$ Ordu Üniversitesi Ziraat Fakültesi Tarla Bitkileri Bölümü, Ordu \\ 20rdu Üniversitesi Tıp Fakültesi Biyoistatistik ve Tıbbi Bilișim Anabilim Dalı, Ordu \\ ${ }^{3}$ Ondokuz Mayıs Üniversitesi Ziraat Fakültesi Tarla Bitkileri Bölümü, Samsun
}

*Bu çalışma 19-23 Haziran 2018 tarihlerinde gerçekleşen “International Symposium Ecology 2018” adlı sempozyumda sözlü bildiri olarak sunulmuș ve bildiri özeti olarak basılmıștır.

Alınış tarihi: 19 Temmuz 2018, Kabul tarihi: 20 Kasım 2018

Sorumlu yazar: Gürkan DEMIRKOL, e-posta: gurkandemirkol@odu.edu.tr

Öz

Kaliteli kaba yem açı̆̆ı bulunan ülkemizde yem bitkisi ekim alanının arttırılması büyük önem taşımaktadır. Türkiye'de Karadeniz Bölgesi'nde yoğun olarak üretimi gerçekleștirilen fındık bahçelerinde alt bitki olarak yem bitkisi yetiştiriciliğinin yapılması kaba yem açığımızın kapatılmasında önemli potansiyele sahiptir. Findık bahçesinde alt bitki olarak yetiştirilen yaygın fiğ, tritikale ve yulaf karışımlarının (\% 50 fiğ $+\% 50$ tritikale ve \%50 fiğ $+\% 50$ yulaf) ot verimini belirlemek amacıyla yürütülen bu araştırmada; karışımların doğal vejetasyona göre daha fazla miktarda kaba yem ürettiği ve aynı zamanda yabancı otları önemli düzeyde baskıladığı tespit edilmiştir. Çalışmada fiğ+tritikale karışımından $478 \mathrm{~kg} / \mathrm{da}$, fiğ+yulaf karışımından ise $222 \mathrm{~kg} / \mathrm{da}$ kuru ot elde edilmiştir. Sonuç olarak, arazi yapısının uygun olduğu alanlarda fındık bahçesi altında yem bitkisi yetiştiriciliği önerilmektedir.

Anahtar kelimeler: Alternatif yem kaynağı, Avena sativa, Corylus avellana, Vicia sativa

Determination of hay yield of common vetch+cereal mixtures grown under hazelnut orchards

\footnotetext{
Abstract

Increasing the forage cultivation area is extremely important in Turkey due to high gap in quality forage. The culture of forage crops under the
}

hazelnut, which is produced intensively in Black Sea Region of Turkey, has the potential to be an alternative in the resolve of quality forage deficient. In this research which conducted to determine the hay yield of common vetch, triticale and oat mixtures (50\% common vetch $+50 \%$ triticale and $50 \%$ common vetch $+50 \%$ oat) grown under hazelnut orchards, it was found that the mixtures had more roughage and more suppression potential than natural vegetation significantly. In the study, 478 $\mathrm{kg} / \mathrm{da}$ in common vetch + triticale mixture, 222 $\mathrm{kg} / \mathrm{da}$ in common vetch + oat mixture were obtained. As a result, forage cultivation under hazelnut orchards is suggested in suitable land structure areas.

Key words: Alternative forage source, Avena sativa, Corylus avellana, Vicia sativa

\section{Giriş}

Ülkemizde hayvancıllı̆ı̆ı yeniden canlanması için mutlaka karlı bir üretimin yapılması gerekmektedir. Hayvansal üretimde girdilerin büyük kısmını yem maliyetleri oluşturmaktadır. $\mathrm{Bu}$ nedenle yem maliyetleri ne kadar düșürülürse hayvancıllk o kadar karlı olacaktır. Ruminantların sağlıklı yaşamaları için kaba yem tüketmeleri gerekmektedir. Türkiye'de gerek mera alanlarının düşük verimli olması gerekse tarla tarımı içinde yem bitkilerinin ekilișinin az olması nedenleriyle, mevcut hayvanların kaba yem ihtiyacının karșılanamadığı bilinmektedir (Acar ve ark., 2015). Bu nedenle ülkemizde kaba yem üretimini artırmak için yeni alternatiflere ihtiyaç 
duyulmaktadır. Meyve bahçelerinde alt bitki olarak yem bitkisi yetiştirilmesi hem yem bitkisi üretimini arttıracak hem de bu alanlarda yabancı otlarla mücadele olanağı sağlayacaktır. Nitekim, Türkiye'de yaklaşı 3 milyon ha alanda meyve bahçesi, Karadeniz Bölgesi'nde ise yaklaşık 700 bin ha alanda fındık bahçesi bulunmaktadır (TÜİK, 2017).

Karadeniz Bölgesi'nde findık tarımı yapılan alanlarda, hem yıllık toplam yağış miktarı yüksek hem de yağışın yıl içinde dağılımı nispeten düzenlidir. $\mathrm{Bu}$ nedenle findık bahçelerinde doğal vejetasyon oldukça iyi gelişmektedir.

Fındık plantasyonlarında gelişen otsu vejetasyon erken dönemlerde, otlatılarak veya biçilerek kaba yem kaynağı olarak değerlendirilmektedir (Albayrak ve ark., 2008). Fındık hasadına yakın dönemde ise fındık hasadının daha kolay yapılması için biçerek veya herbisit uygulayarak yok edilmeye çalışılmaktadır. Özellikle ısırgan, bögürtlen gibi bitkilerin yoğun olduğu bahçelerde total herbisit kullanılarak bu türlerle mücadele edilmektedir. Herbisit kullanımının çevreye olan zararı da dikkate alındığında, söz konusu alanlarda yem bitkileri yetiştiriciliği ile yabancı otlarla mücadele çevre dostu bir uygulama olarak karşımıza çıkmaktadır.

$\mathrm{Bu}$ çalışma findık bahçesinde alt bitki olarak yetiştirilen $\% 50$ yaygın fiğ+\% 50 tritikale ve $\% 50$ yaygın fiğ+\% 50 yulaf karışımlarının ot verimini ve karışımların yabancı otları baskılama gücünü belirlemek amacıyla yürütülmüştür.

\section{Materyal ve Yöntem}

Araştırma Giresun ili Keşap ilçesinde yöre çiftçisine ait findık bahçesinde $\left(40^{\circ} 55^{\prime} \mathrm{N}, 38^{\circ} 31^{\prime} \mathrm{E}\right)$ yürütülmüştür. Fındık bahçesinde doğal olarak yetişen bazı türler Çizelge 1'de verilmiştir.

Çizelge 1. Fındık bahçesinde doğal olarak yetişen bazı türler

\begin{tabular}{l}
\hline Plant species \\
\hline Fragaria vesca \\
Trachystemon orientalis \\
Urtica sp. \\
Rubus sanctus \\
Trifolium repens \\
Trifolium pratense \\
Poa sp. \\
Dactylis glomerata \\
\hline
\end{tabular}

Araştırmanın yürütüldüğü bahçenin toprak yapısı incelendiğinde killi tınlı bünyede, hafif asit (pH: 5.58), az kireçli $\left(\mathrm{CaCO}_{3} \%\right.$ 0.42), organik madde ve fosfor içeriği az (sırasıyla \% 2.71, 1.98 ppm), potasyum içeriği ise yeterlidir (154 ppm). Giresun illerinde araştırmanın yürütüldüğü 2016-2017 vejetasyon dönemi ve uzun yllar ortalamasina ait sıcaklık ve yağış değerleri incelendiğinde, bölgenin vejetasyon süresi içinde Nisan ayı hariç yağışlı ve serin geçtiği görülmektedir (Çizelge 2).

Çizelge 2.Giresun ili iklim verileri (Anonim, 2017)

\begin{tabular}{|c|c|c|c|c|c|c|c|c|c|}
\hline & & \multicolumn{7}{|c|}{ Aylar } & \multirow[b]{2}{*}{ Top/ort } \\
\hline & & Kasım & Aralık & Ocak & Șubat & Mart & Nisan & Mayıs & \\
\hline \multirow{2}{*}{$\begin{array}{c}\text { Toplam } \\
\text { yağış } \\
\text { (mm) }\end{array}$} & $\begin{array}{l}\text { Uzun } \\
\text { yillar }\end{array}$ & 136.9 & 130.8 & 86.8 & 93.1 & 144.0 & 120.5 & 106.9 & 819.0 \\
\hline & $\begin{array}{c}2016- \\
2017\end{array}$ & 120.5 & 256.3 & 103.8 & 144.3 & 95.9 & 57.2 & 119.6 & 897.6 \\
\hline \multirow{2}{*}{$\begin{array}{c}\text { Ortalama } \\
\text { sicaklık } \\
\left.{ }^{\circ} \mathrm{C}\right)\end{array}$} & $\begin{array}{l}\text { Uzun } \\
\text { yillar }\end{array}$ & 11.1 & 4.6 & 5.5 & 6.0 & 6.6 & 8.7 & 14.7 & 8.2 \\
\hline & $\begin{array}{c}2016- \\
2017\end{array}$ & 9.8 & 2.1 & 2.9 & 4.3 & 8.4 & 10.1 & 13.6 & 7.3 \\
\hline
\end{tabular}

Araştırmada yaygın fiğ (Vicia sativa), yulaf (Avena sativa) ve tritikale (Triticosecale Witmax) ile karışık ekilmiştir. Karışımlar \%50 fiğ + \% 50 tahıl olacak şekilde ekilmiştir. 3 bitki türünde de yerel çeşitler kullanılmıştır. Ekim öncesinde fındık bahçesi bahçe traktörü ile çapalanarak tohum yatağı hazırlanmıştır. Ekim, kasım ayının ikinci yarısında $50 \mathrm{~m}^{2}$ (5x10) lik alanlara elle serpme olarak yapılmıștır. Ekimde fiğ, tritikale ve yulaf için sırasıyla 5,10 ve $8 \mathrm{~kg} / \mathrm{da}$ tohum kullanılmıştır. Ekimle birlikte $5 \mathrm{~kg} \mathrm{~N} / \mathrm{da}$ ve 8 $\mathrm{kg} \mathrm{P}_{2} \mathrm{O}_{5} /$ da olacak şekilde gübreleme yapılmıştır. Araştırmada ayrıca hiçbir işlemin uygulanmadığı kontrol parseli $\left(50 \mathrm{~m}^{2}\right)$ yer almıştır. Kontrol parseli çiftçinin fındık bahçesindeki uygulamasını yansıtmak amaciyla düzenlendiğinden, otsu vejetasyona gübreleme de yapılmamıştır. Hasat 19 Mayıs 2017'de yapılmıştır. Hasat tarihi hem bitkilerin gelişimi hem de fındık bahçelerinde bahar bakım işlemlerinin yapıldığı dönem dikkate alınarak belirlenmiștir. Hasat tarihinde fiğde alt baklalar oluşmuşken, tritikale ve yulaf çiçeklenme dönemindedir. Hasat sırasında 3 işlemde de $50 \mathrm{~m}^{2}$ lik alandan tesadüfi olarak $50 \quad \mathrm{~cm} \quad$ x $50 \quad \mathrm{~cm}$ 'lik quadratların içindeki bitkiler biçilmiştir. Fiğ+tahıl 
karışımlarında 20 adet, kontrol parselinde ise 10 adet quadrat hasat edilmiştir. Karışım parsellerinde hasat edilen toplam biomass fiğ+tahıl ve yabancı ot olarak ayrilmış, dekara yeşil ot verimi ve yabancı ot miktarı hesaplanmıștır. Kontrol parselinde ise sadece hayvanların yediği bitkiler ot verimini hesaplamada kullanılmıştır. Her quadrattan alınan örnekler $60^{\circ} \mathrm{C}$ de sabit ağırlı̆̆ gelene kadar kurutulmuş ve kuru ot verimi hesaplanmıştır. Ayrıca fiğ+tahıl karışımlarında toplam biomass içinde yabancı ot oranı hesaplanmıştır.

\section{İstatistik analiz}

Veriler önce Kolmogorov-Smirnov testi ile normallik ve Brown-Forsythe testi ile homojenlik açısından test edilmiștir. Veriler normallik ve homojenlik varsayımlarını yerine getirmediğinden, Karşılaştırmalar non-parametrik testler olan Kruskal-Wallis testi veya Mann-Whitney U-testi kullanılarak yapılmıştır. Uygulamalar arasındaki farkı belirlemek için Dunn'ın post hoc testleri kullanılmıştır. İstatistiksel analiz SPSS v25 (IBM Inc., Chicago, IL, USA) istatistik yazılımı kullanılarak gerçekleştirilmiştir.

\section{Bulgular ve Tartışma}

Yapılan istatistik analiz sonucunda, findık altından elde edilen yeşil ot verimi bakımından işlemler arasında önemli derecede $(\mathrm{p}<0.001)$ farklıllk olduğu belirlenmiștir. Beklenildiği üzere en düșük ot verimi fındık altında doğal olarak yetișen bitkilerden (kontrol) elde edilmiștir (Çizelge 3).

Çizelge 3. Fındık altından elde edilen yeşil ot verimi (kg/da)

\begin{tabular}{cccccccc}
\hline Uygulamalar & $\mathrm{n}$ & Ortalama & Median & IQR & Mean Rank & Min & Max \\
\hline Kontrol & 10 & 274.4 & 264 & 308 & $5.5 \mathrm{C}$ & 40 & 532 \\
$\mathrm{~F}+\mathrm{T}$ & 20 & 1839.4 & 1644 & 611 & $39.5 \mathrm{~A}$ & 752 & 4264 \\
$\mathrm{~F}+\mathrm{Y}$ & 20 & 855.2 & 752 & 417 & $21.6 \mathrm{~B}$ & 544 & 1296 \\
\hline P-değeri & \multicolumn{7}{c}{$0.000^{* * *}(\mathrm{H}=38.61)$} \\
***, istatistiki olarak önemli (p<0,001), Aynı harfi içermeyen uygulamalar istatistiki olarak farklıdır (P<0.05); F: fiğ, T: triticale, Y: yulaf \\
Median, IQR ve Mean Rank sırası ile parametrik olmayan değerler için ortalama, standart sapma ve sıralama için kullanılan değerlerdir.
\end{tabular}

Doğal vejetasyonda bulunan bütün bitkiler hayvanlar tarafından tüketilmemektedir. Hayvanların yemediği bitkiler hayvanların yediği bitkilerle hem su, besin ve ışık rekabetine girerek onların verimini düşürmekte hem de toprağı kaplayarak diğer bitkilere yer bırakmamaktadırlar. Bölgenin iklim koşullarına iyi uyum sağlamış, kaldirik (Trachystemon orientalis), yakıcı özellikteki ısırgan (Urtica sp), dikenli böğürtlen (Rubus sp) gibi bitkilerin bulunduğu alanlar neredeyse hayvanlar tarafından hiç değerlendirilememektedir. Araştırmanın yürütüldüğü bahçede bu bitkiler bulunmaktadır
(Çizelge 1). Yukarıda bahsedilen türler dışında da hayvanlar tarafından tüketilmeyen birçok bitki türü yabancı ot olarak bulunabilmektedir. Bu nedenlerle fındık altında doğal olarak yetişen bitki örtüsünden elde edilen ot verimi düşük olmuştur. Fiğ, yulaf ve tritikale tek ylllk ve iri habitusa sahiptir. Ekimle birlikte karışımlara N ve P uygulaması yapılmışken, kontrol parseline verilmemiștir. Aynı zamanda baklagil olan fiğ biyolojik azot fiksasyonu ile tahıllara ilave N sağlayarak onların daha iyi gelişmesini teşvik etmiştir. Tüm bu nedenlerle karışımların verimi doğal vejetasyona göre oldukça yüksek bulunmuștur.

Çizelge 4. Fındık altından elde edilen kuru ot verimi (kg/da)

\begin{tabular}{llllllll}
\hline Uygulamalar & $\mathrm{n}$ & Ortalama & Median & IQR & Mean Rank & Min & Max \\
\hline F+T & 20 & 478.244 & 427.44 & 158.86 & $29.4 \mathrm{~A}$ & 195.52 & 1108.64 \\
$\mathrm{~F}+\mathrm{Y}$ & 20 & 222.352 & 195.52 & 108.42 & $11.6 \mathrm{~B}$ & 141.44 & 336.96 \\
\hline P-değeri & $0.000^{* * *}(\mathrm{~W}=589.0)$ \\
\hline
\end{tabular}

Fiğ+tritikale karıșımının fiğ+yulaf karıșımına göre daha fazla $(\mathrm{p}<0.05)$ kuru ot verimi sağladığı görülmektedir (Tablo 2). Bu durum muhtemelen iki tahıl türünün iklim, toprak istekleri, kardeșlenme özellikleri, bitki boyu ve yaprak yapısı gibi farklılıklar sonucu ortaya çıkmıştır (Önal Aşcı ve
Eğritaș, 2017). Bilindiği üzere tritikale yulafa göre daha uzun boylu, az kardeşlenir ve daha dar yaprak ayasına sahiptir. Toprak isteği yulaftan daha az ve kuraklığa dayanımı yulaftan fazladır (Geçit ve ark., 2009). İlkim verileri incelendiğinde nisan ayının uzun yıllar ortalamasına göre oldukça kurak ve daha 
sıcak geçtiği görülmektedir. Nisan ayında yaşanan bu kuraklıktan yulaf muhtemelen tritikaleye göre daha fazla olumsuz etkilenmiştir. Ayrıca arazi eğimli olduğundan sığ toprak yapısına sahiptir. Yanısıra baharda findık bitkilerinde yaprak oluşumu ile birlikte yem bitkilerine gölgeleme, su ve besin

Çizelge 5. Karışımdaki yabancı ot oranı (\%)

\begin{tabular}{cccccccc}
\hline Uygulamalar & $\mathrm{n}$ & Ortalama & Median & IQR & Mean Rank & Min & Max \\
\hline F+T & 20 & 6.161 & 3.08 & 6.551 & 24.6 B & 0.0 & 47.92 \\
F+Y & 20 & 1.605 & 0.00 & 0.000 & 16.4 A & 0.0 & 11.75 \\
\hline P-değeri & & \multicolumn{7}{c}{$0.013^{*}(\mathrm{~W}=493.0)$} \\
\hline
\end{tabular}

*, istatistiki olarak önemli ( $\mathrm{p}<0,05)$; Aynı harfi içermeyen uygulamalar istatistiki olarak farklıdır $(\mathrm{P}<0.05)$; F: fiğ, T: triticale, Y: yulaf

Median, IQR ve Mean Rank sırası ile parametrik olmayan değerler için ortalama, standart sapma ve sıralama için kullanılan değerlerdir.

Karışımlarda doğal vejetasyona ait bitkilerin bulunma durumu yabancı ot oranı olarak belirlenmiştir. Her iki karıșım içinde de yabancı ot oranının oldukça düşük kaldığı görülmektedir (Çizelge 5). Ekim işleminden önce tam olmasa da bir toprak işlemenin yapılması yabancı ot gelişimini engellemiştir. Toprak işlemenin yabancı otlarla mücadele yöntemi olduğu bilinen bir gerçektir. Ayrıca karışımlarda kullanılan türlerin tohumları iridir ve güçlü fideler oluşturmaktadır. Bu özelliği ile bitkiler kısa sürede toprağı kaplayabilmektedir. Bitkilerin baharda gelişim hızları da yüksek ve iri habitusa sahiptirler. Tüm bu özellikleri ile doğal vejetasyonu yok etmede oldukça yüksek performans sergilemişlerdir. Çizelge 5'te görüldüğü üzere fiğ+yulaf karışımı, fiğ+tritikale karışımına göre yabancı otları daha iyi baskılayabilmiştir. Karışımda kullanılan iki tahıl türü, kardeşlenme özelliği ve yaprak yapısı bakımından birbirinden farklıdırlar. Yulaf tritikaleye göre daha fazla kardeşlenmektedir ve daha geniş yaprak ayasına sahiptir. Yulaf aynı zamanda allelopatik özelliği olan bir türdür. Yulafın üçgül (Trifolium sp.) türleri üzerinde allelopatik etkisi olduğu bilinmektedir (Gürsoy ve ark., 2013). Çalışmanın yürütüldüğü arazide Trifolium türleri doğal olarak yetişmektedir (Çizelge 1). Tüm bu nedenlerle yulaf+fiğ karışımının yabancı otlar ile rekabeti daha yüksek olmuştur.

\section{Sonuç}

Sonuç olarak findık altında fiğ tritikale veya fiğ+yulaf karışımı yetiştirmek doğal vejetasyona göre daha fazla kaba yem üretmiştir. Ancak \% 50 fiğ+\% 50 tritikale karıșımından elde edilen kuru ot verimi (478 kg/da), fiğ+yulaf karışımdan önemli derecede rekabeti yaşanmaya başlanmıştır. Daha öncede ifade edildiği üzere tritikalenin toprak isteği daha azdır. Tüm bu nedenlerle fiğttritikale karışımında verimin yüksek olduğu düşünülmektedir. Nitekim arazide de tritikalenin yulafa göre daha iyi geliştiği görülmüștür. yüksek bulunmuştur. Bölgede her ne kadar tüm findık bahçelerinde alt bitki olarak yem bitkisi yetiștiriciliği mümkün olmasa da arazi yapısının (özellikle eğim ve toprak kalınlığının) izin verdiği alanlarda, \% $50 \quad$ fiğ $+\% \quad 50$ tritikale karışımı yetiştirilerek kaba yem üretimi arttırılabilir. Ayrıca findık bahçelerinde yabancı otlar da kontrol altında tutulabilir.

\section{Kaynaklar}

Acar, Z., Sabancı, C.O., Tan, M., Sancak, C., Kızılşimşek, M., Bilgili, U., Ayan, İ., Karagöz, A., Mut, H., Önal Așcı, Ö., Başaran, U., Kır, B., Temel, S., Yavuzer, G. B., Kırbaş, R., Akça Pelen, M., 2015. Yem bitkileri üretiminde değişimler ve yeni arayışlar Türkiye Ziraat Mühendisliği VIII. Teknik Kongresi, Bildiriler Kitabı-1, 508-547, 12-16 Ocak 2015, Ankara.

Albayrak, S., Töngel, Ö., Ayan, İ., Acar, Z., 2008. Nitrogen and phosphorous fertilizer improve pastures naturally growing under hazelnut trees. Acta Agriculturae Scandinavica Section B-Soil and Plant Science, 58(2): 154-161.

Anonim, 2017. Meteoroloji genel müdürlüğü.

Geçit, H. H., Emeklier, Y., İkincikarakaya, S., Adak, M. S., Kolsarıcı, Ö., Ekiz, H., Altınok, S., Sancak, C., Sevimay, C. S., Kendir, H. 2009. Tarla Bitkileri. Ankara Üniversitesi Ziraat Fakültesi Yayınları. Yayın No: 1569, Ders Kitabı: 521. Ankara. 540 s.

Gürsoy, M., Balkan, A., Ulukan, H., 2013. Bitkisel üretimde allelopati. Uludağ Üniversitesi Ziraat Fakültesi Dergisi, 27(2): 115-122.

Önal Așcl, Ö., Eğritaş, Ö., 2017. Yaygın Fiğ-Tahıl Karışımlarında Ot Verimi, Bazı Kalite Özellikleri ve Rekabetin Belirlenmesi. Tarım Bilimleri Dergisi, 23(2): 242-252.

TÜİK, 2017. Tarımsal Verileri. http://www.tuik.gov.tr 